\title{
Diagnosis and Treatment Procedures Involved for Young Female Patients having Fibroadenoma
}

\author{
Debasmita Chatterjee*, Rathin Chakravarty, Bishaka Halder, Asutosh Kundu, \\ Suparna Mukherjee and Satadal Das
}

Department of Immunogenetics, Dr. Bholanath Chakravarty Integrated Medical Research and Treatment Centre, Kolkata, India

*Corresponding author

\section{A B S T R A C T}

\section{Keywords}

Fibroadenoma

(FA), High

Resolution

Ultrasonography

(HRUSG), X-Ray

Mammogram,

Hormonal

regulation,

Treatment options

Article Info

Accepted:

04 December 2018

Available Online:

10 January 2019

\begin{abstract}
'Fibroadenoma', is the most common benign tumors among most of the young female patients who are in their adolescent phase. They can be asymptomatic or painful and sometimes develop as tumors which cause distortions of breast. Here we have conducted a descriptive 6 months survey from April to September, 2018 at Dr. Bholanath Chakravarty Integrated Medical Research and Treatment Centre. All the clinical records along with the consent of the patients were taken and recorded for future analysis. It was observed that among selected 113 patients attending the OPD, 11 patients $(9.73 \%)$ were found as confirmed cases of fibroadenoma via diagnostic techniques ultrasonography and X-Ray Mammogram. Fibroadenomas are more frequent among married woman than unmarried woman. The factors such as early marriage and parity, age of menarche and age of menopause, hormonal therapy such as intake of oral contraceptives have no effect on these lesions. Our study revealed that the incidence percentage of fibroadenoma out of 113 cases were $11(9.73 \%)$. Patients who undergo conservative therapy involves combination of progesterone and danazol as it is the most accepted theory for the treatment.
\end{abstract}

\section{Introduction}

'Fibroadenoma', a common benign breast mass often noticed among young female patients within 35 years of age. They are often felt as smooth rubbery or hard palpable mass similar to a structure of pea or grape (Begum et al., 2017). The structure is not considered to be true neoplasms, rather an eccentricity of normal development of breast (Greenberg et al., 1998). As they are considered to be benign breast lesions, therefore there are two mode of suggestive treatment for the disease, i.e., conservative mode of treatment where it could be assumed that surgical excision is not needed and the structure could regress eventually and the other method is surgical excision method (Santhosh et al., 2018). There are mainly two issues to consider with the enlargement of FAs: 1) probable 
development of malignancy in the epithelial component, 2) the possibility of progression of FA into phyllodes tumor (PT) (Sanders et al., 2015). Histological examination revealed that FA resembles hyperplastic breast lobule and they also respond to hormonal stimulation in the same manner as normal breast tissue does (Begum et al., 2017). The biological nature of fibroadenoma is unpredictable as they may remain static or grow rapidly (Begum et al., 2017).

Initially surgical excision was considered to be the only mode of treatment for FAs to avoid the development of malignancy. Fortunately this doctrine has been recently challenged because confident diagnosis with preoperative investigations excludes the need for surgical excision (Begum et al., 2017). There are basically three categories of FAs: 1) simple fibroadenoma, 2) giant juvenile fibroadenoma and multicentric fibroadenoma (Begum et al., 2017).

\section{Fibrocystic disease}

Patients have lumpy breast rather than the classical lump. Pain, nipple discharges are the two major clinical features observed among these patients though exact pathogenesis is unknown. Hormone estrogen predominates over progesterone which plays the key role in the development of the disease. Core biopsy is suggested as the tool for confirmatory diagnosis (Hartmann et al., 2005; Marshall et al., 1997; Kennedy et al., 2003; Patterson et al., 2004; Fasih et al., 2005; Rabban et al., 2004).

\section{Phyllodes tumor}

PT represents the most common benign tumor of the breast which enlarges rapidly. It represents a spectrum of diseases which ranges from FA to benign, metastasising benign and malignant PT. Large PT are expected to become malignant and may represent pain and according to the data available from previous studies, $38 \%$ of PT turned out to be malignant and rest are all sarcomas (Vijayalakhmi et al., 2016).

\section{Adenomyoepithelioma}

It is considered to be a rare benign tumor condition of the breast and it is difficult to clinically differentiate from carcinoma. After surgical excision the recurrence rates are also high, therefore mastectomy is the only choice left for those patients. Fine Needle Aspiration Cytology (FNAC) confirms the diagnosis with $86 \%$ of specificity and $99 \%$ of sensitivity. Core biopsy acts as a confirmatory tool for doubtful cases (Vijayalakhmi et al., 2016).

\section{Materials and Methods}

A descriptive observational study was conducted for 6months, from April to September, 2018. A total number of 113 cases were selected for our study, investigated and confirmed by physical examinations followed by ultrasonography and X-Ray mammogram study. The detailed history and clinical examination of all patients were also recorded.

\section{Inclusion criteria for the patients are}

1. Female patients showing breast lump.

2. Ages of the patients were more than 12 years.

3. Patients admitted in between the study period.

4. Cases confirmed by physical examinations and sonography.

\section{Exclusion criteria for the patients are}

1. Male Patients.

2. Ages of the patients were less than 12 years.

3. Patients having any congenital abnormalities. 
4. Patients having inflammatory condition of the breast or having breast carcinoma.

\section{Results and Discussion}

\section{Age distribution and its significance}

According to previous literatures, higher numbers of cases of fibroadenomas (FAs) are observed among the second and third decade (Table 1) (Frantz et al., 1951). Hormonal change especially estrogen is considered to be the major reason behind fibroadenoma as it changes their size during pregnancy, menstruation and also during lactating phase (Soini et al., 1981; Ajitha et al., 2012) (Fig. 1 and 2).

Table.1 Age wise distribution of patients

\begin{tabular}{|c|c|c|c|}
\hline Sl. No. & Age Group & No. Of Patients & Percentage (\%) \\
\hline 1 & $10-20$ & 2 & 20 \\
\hline 2 & $21-30$ & 5 & 45.45 \\
\hline 3 & $31-40$ & 4 & 40 \\
\hline
\end{tabular}

Table.2 Clinical features observed for the confirmed cases by physical examination and ultrasonography / Mammography

\begin{tabular}{|c|c|}
\hline $\begin{array}{c}\text { Patient } \\
\text { Code }\end{array}$ & Clinical Features \\
\hline BNC 006 & Multiple benign fibroadenoma of left breasts \\
\hline $\begin{array}{c}\text { BNCH } \\
010\end{array}$ & $\begin{array}{l}\text { Surgery was done, FA in both breasts. Important Features are } \\
\text { fibroadenomas in both breasts (birads ii category). }\end{array}$ \\
\hline $\begin{array}{c}\text { BNCH } \\
011\end{array}$ & Fibroadenoma, Benign FA - left breast, Right breast. \\
\hline $\begin{array}{l}\text { BNCH } \\
016\end{array}$ & Benign fibroadenoma at lower lateral part of right breast. \\
\hline $\begin{array}{c}\text { BNCH } \\
019\end{array}$ & $\begin{array}{l}\text { Small benign hypoechogenic is visible in lower lateral area of right breast. } \\
\text { May be benign fibroadenoma in right lower lateral part of the breast. }\end{array}$ \\
\hline $\begin{array}{c}\text { BNCH } \\
\text { 050 }\end{array}$ & Finding more suggestive of fibroadenoma of both breast. \\
\hline $\begin{array}{c}\text { BNCH } \\
056\end{array}$ & Finding more suggestive of fibroadenoma of left breast. \\
\hline $\begin{array}{c}\text { BNCH } \\
080\end{array}$ & $\begin{array}{c}\text { Inflammatory breast lesion. Suggestive of fibroadenoma of breast via } \\
\text { HRUSG }\end{array}$ \\
\hline $\begin{array}{l}\text { BNCH } \\
082\end{array}$ & $\begin{array}{l}\text { USG finding shows bilateral fibroadenoma with X - Ray mammogram and } \\
\text { HRUSG }\end{array}$ \\
\hline $\begin{array}{c}\text { BNCH } \\
097\end{array}$ & $\begin{array}{l}\text { Fibroadenoma in right breast. Clinical correlation using X-Ray } \\
\text { mammography and HRUSG are suggested for patients for further } \\
\text { evaluation. }\end{array}$ \\
\hline $\begin{array}{l}\text { BNCH } \\
112\end{array}$ & $\begin{array}{l}\text { Fibroadenoma in right breast. Clinical correlation using X-Ray, } \\
\text { mammogram and HRUSG are suggested for patients for further evaluation. }\end{array}$ \\
\hline
\end{tabular}

FA: Fibroadenoma

HRUSG: High Resolution Ultrasonography 
Fig.1 Mode of treatment employed for fibroadenoma cases (FA) among female patients within 35 years of age (Greenberg et al., 1998)

\section{Mode of Treatment for patients having Fibroadenoma:}

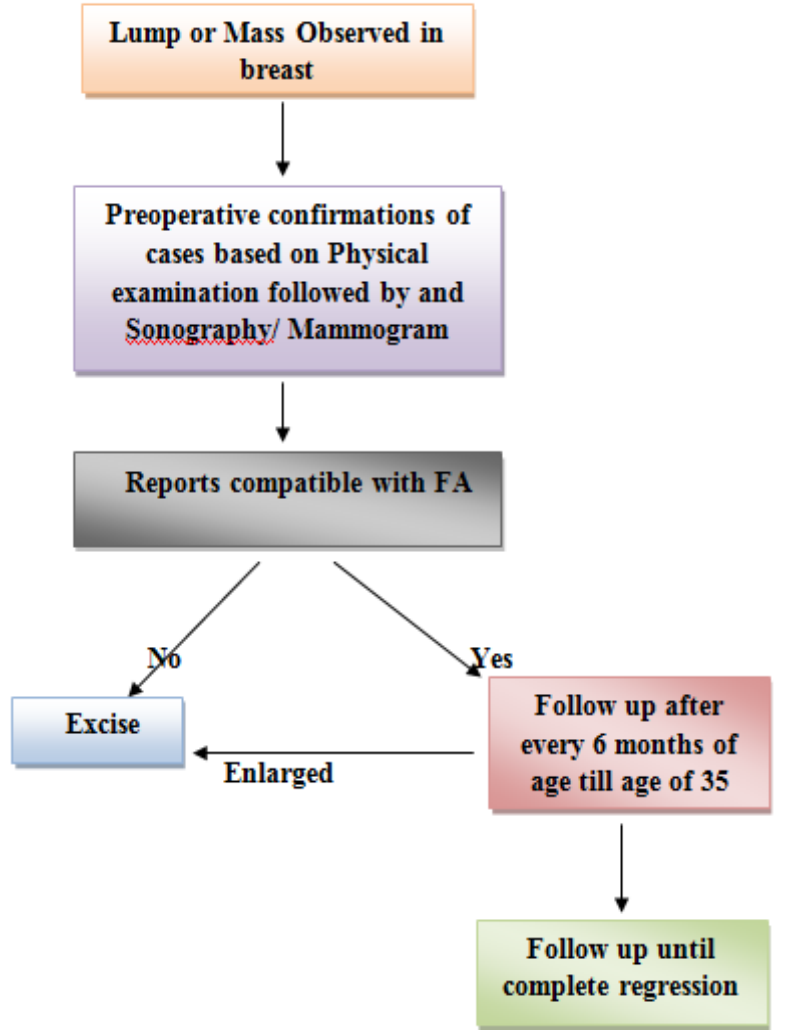

Fig.2 The picture represent the simplified anatomy of the female breast explaining the major structural components of the breast which includes the anatomic location of various lesions along with their histology indicating the potential lesion ((Kotepui et al., 2014)

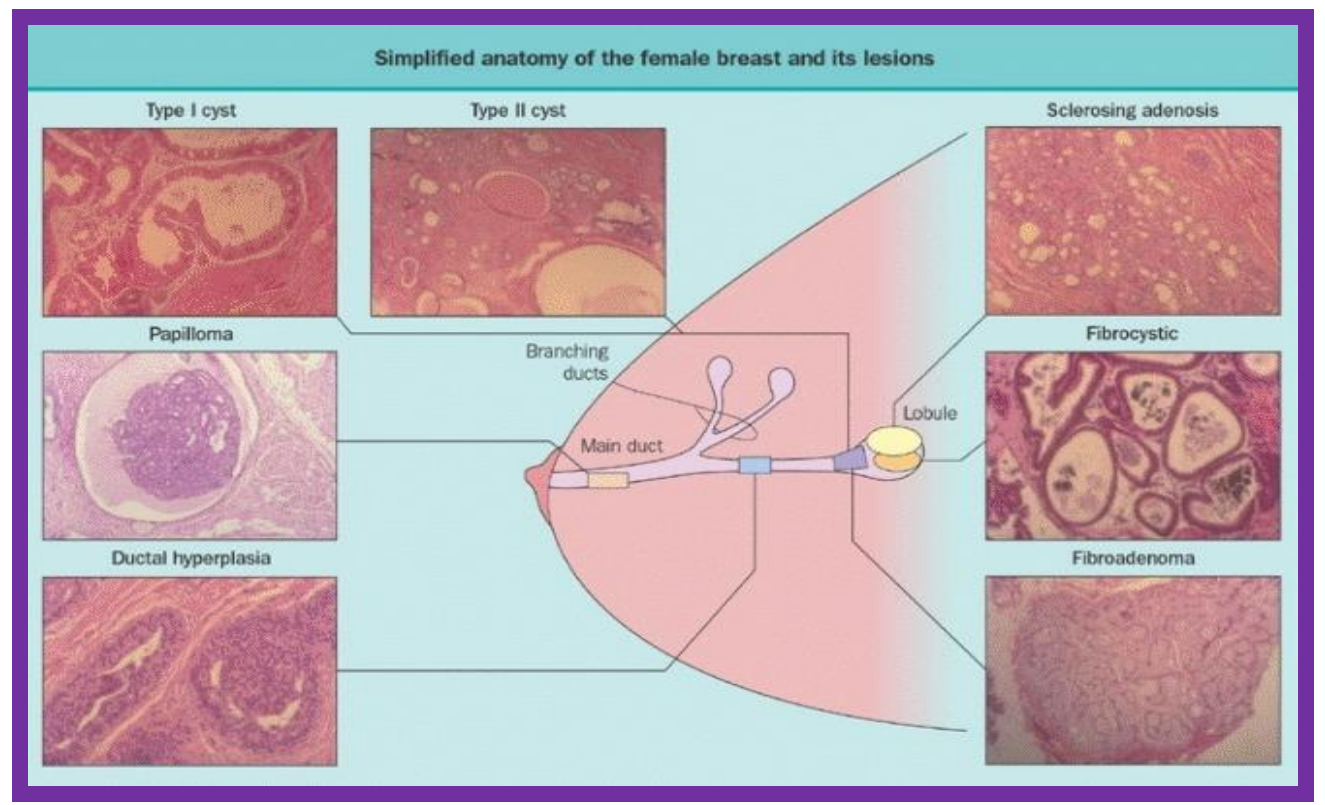


Fig.3 The graph describes the location and percentage of fibroadenoma patients among the confirmed cases

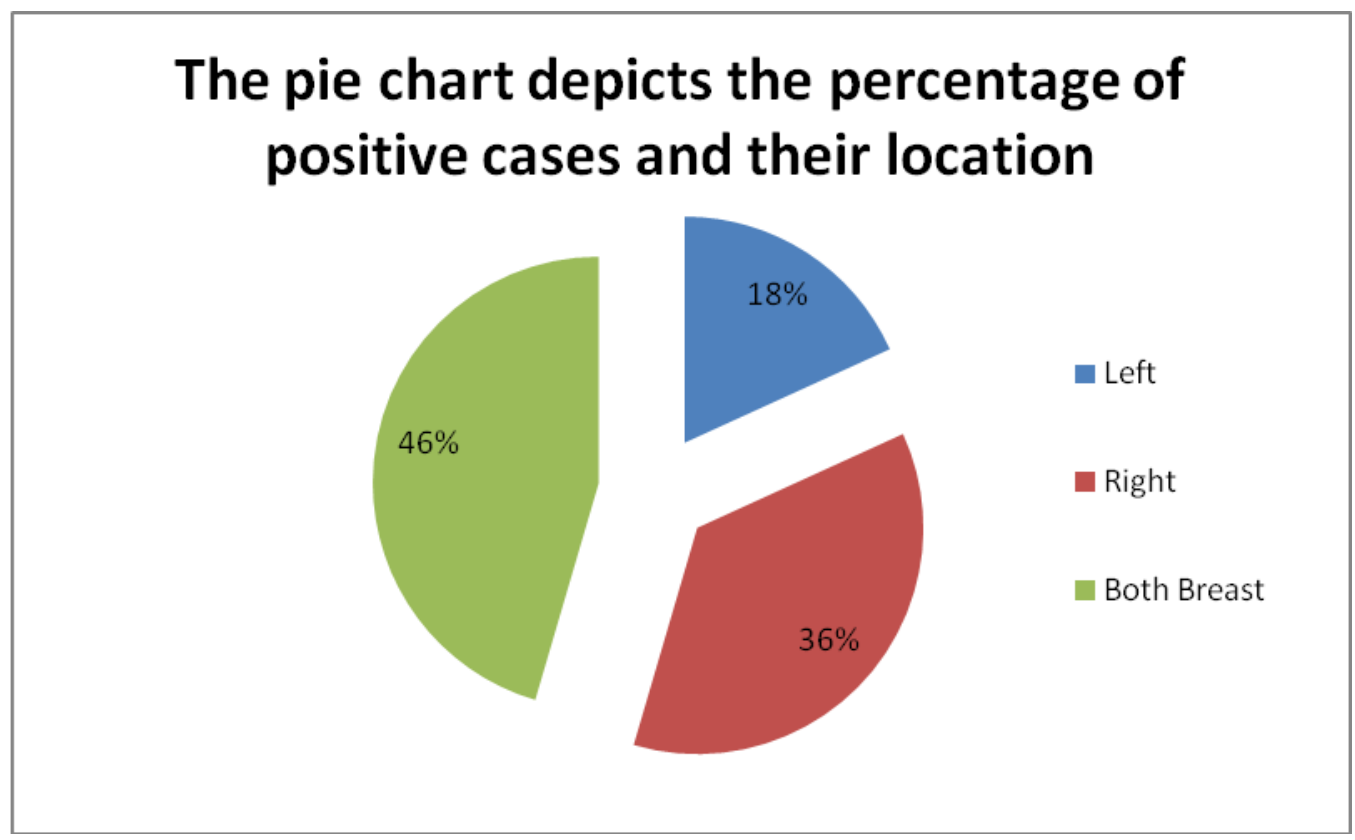

Fig.4 The visualized sonographic image region reveals a focal bulge of homogeneous soft tissue density of size approximately $20.39 \mathrm{~mm}$ x $12.93 \mathrm{~mm}$, suggestive benign SOL with smooth margins

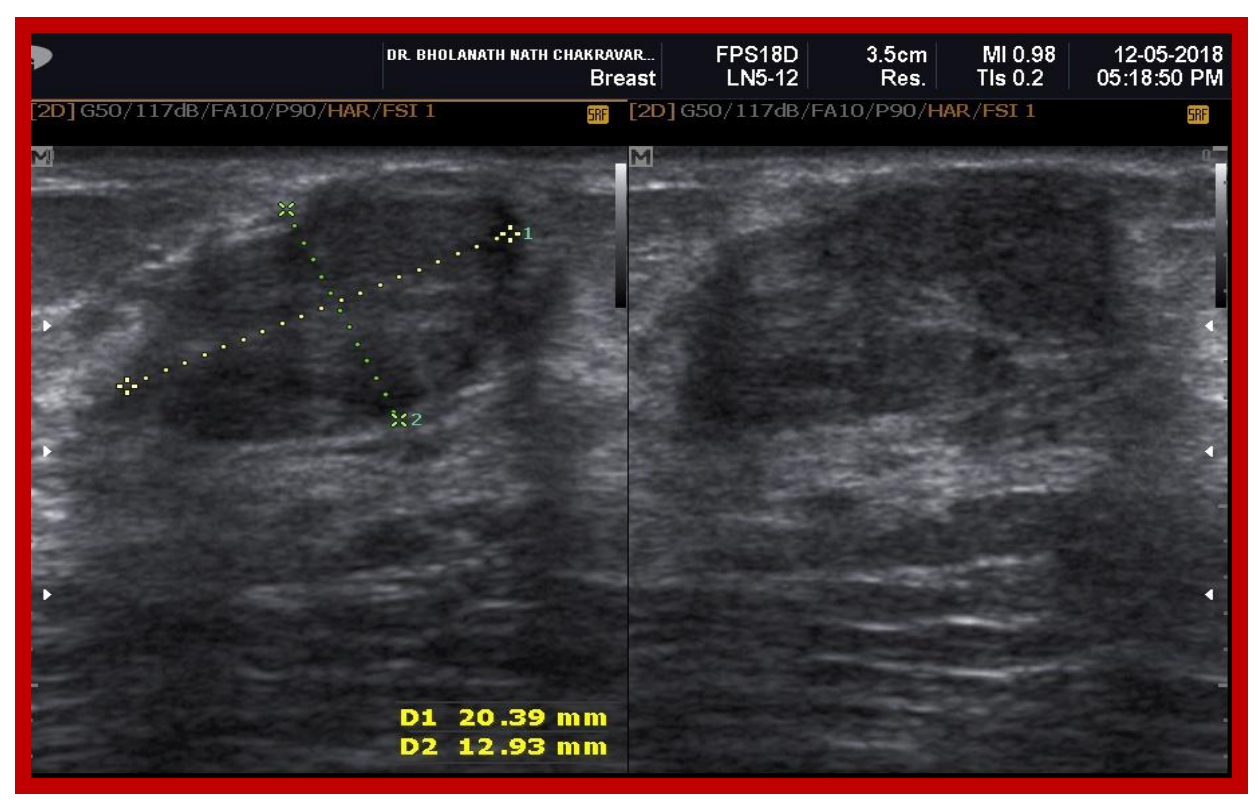

They also undergo autotrophic changes during menopause and have receptors which respond to growth hormone and epidermal growth factor. Menopause is considered to be a probable contribution to lump formation and evolution (Ajitha et al., 2012). According to the data mentioned in previous literatures $72 \%$ of positive cases are reported from urban 
areas and very few cases are reported from rural background (Soini et al., 1981). The major reasons behind this kind of differential case reporting are sedentary life style of urban population, unhealthy food habits especially junk foods. The other reasons that can be considered for higher reporting of cases from urban population are due to high literacy rate and availability of facilities for the screening of breast cancer (Santhosh et al., 2018).

\section{Confirmation of cases by ultrasonography}

This technique has often been used as confirmatory diagnosis of fibroadenoma as the observation reveals round solid mass having smooth contour and weak internal echoes which supports the diagnosis (Table 2) (Fig. 4). This technique may also help us to differentiate between solid and cystic lesions. Previous literature revealed that $25 \%$ of the FAs, showed irregularity indicating malignancy. The sonography data confirmed with biopsy depicted that $82 \%$ of the cases are fibroadenomas. We have also described our data based on the location along with its percentage of the benign mass (Fig. 3). On the other hand the role of mammography for the detection of fibroadenoma among young women is very limited (Greenberg et al., 1998).

\section{Fibroadenoma and association with development of breast cancer}

Literature studies reported that $0.002 \%$ to $0.0125 \%$ cases of developing fibroadenoma are found to be carcinomas (Greenberg et al., 1998). The patients having a history of non complex fibroadenoma and having no history of breast cancer are reported to be at lower risk. Previous literature revealed that $50 \%$ of the tumors are lobular carcinoma in situ (LCIS), 20\% were considered to be ductal carcinoma in situ (DCIS) and the remaining $10 \%$ are infiltrating ductal carcinoma (Ajitha et al., 2012).
According to epidemiological survey data mentioned in other literatures FAs are more frequent among married woman than unmarried woman. The factors such as early marriage and parity, age of menarche and age of menopause, hormonal therapy such as intake of oral contraceptives have no effect on these lesions. Therefore, no definitive associations could be achieved. Patients undergoing conservative therapy involve combination of progesterone and danazol since it is the most accepted theory for the treatment of FA, which occurs due to excessive influence of hormone estrogen. Anti-estrogen medications could not show any effect upon FAs. Therefore, conservative treatment follows clinical examination, radiology and biopsy (Ajitha et al., 2012).

\section{Treatment options}

Patients who don't want to undergo surgery, USG guided cryoablation are advised for them (Lee et al., 2015).

\section{Vacuum assisted percutaneous biopsy}

This process removes tumor through core biopsies and depending on radiographic guidance, the whole procedure gets completed when the mass is completely removed via radiographic means (Lee et al., 2015).

\section{Ablative procedure}

It involves cryotherapy where FA gets removed with a probe which gets subsequently cooled by argon gas to $-160^{\circ}$ C. The cell membrane gets disrupted which results thrombosis of capillaries and results in eventual destruction of FA (Lee et al., 2015).

\section{Surgical excission}

Giant FAs can be removed surgically without causing iatrogenic deformity to the breast (Lee et al., 2015). 
In conclusion, fibroadenomas are more frequent among married woman than unmarried woman. It was observed that among selected 113 patients attending the OPD, 11 patients $(9.73 \%)$ were found as confirmed cases of fibroadenoma via diagnostic the applied diagnostic technique ultrasonography and X-Ray mammogram. Patients who undergo conservative therapy involves combination of progesterone and danazol, as it is the most accepted theory for the treatment (Ajitha et al., 2012).

\section{Acknowledgement}

The authors would like to acknowledge the Institution, for providing all the facilities for performing the study.

\section{Author's contribution}

All the authors have analysed the data and have gone through the final draft of the manuscript.

\section{References}

Begum R, Thomus R, Babu N. 2017. Chances of breast cancer with fibroadenoma Review. J of Sci and Innov Res. 6: $84-$ 86.

Greenberg R, Skornick Y, Kaplan O. 1998. Management of breast fibroadenomas. J of Gen Internal Med. 13: 640 - 645.

Santhosh L, Sangolgi P, Jabshetty S. 2018. Clinical profile of patients with fibroadenoma of breast. Int Surgery J. 5: 1057 - 1061.

Sanders ML. and Sara R. 2015. The growing fibroadenoma. Acta Radiol Open. 4: 15.

Frantz VK, Pickren JW, Melcher GW, Auchincloss H. 1951. Incidence of chronic cystic disease in so called "normal breasts". A study based on 225 postmortem examinations. Cancer. 1: 762-83.
Soini I, Aine R, Lauslahti K, Hakama M. 1981. Independent risk factors of benign and malignant breast lesions. Am $\mathrm{J}$ of Epidemiol. 114: 507-14.

Ajitha MB, Srinivasan N, Shivaswamy BS, Abhishek VK. 2012. A systematic study on fibroadenoma of the breast. Int $\mathbf{J}$ of Biomed and Adv Res. 3: $891-895$.

Hartmann LC, Sellers TA, Frost MH et al., 2005. Benign breast disease and the risk of breast cancer. N Engl J Med. 353: 229-237.

Marshall LM, Hunter DJ, Connolly JL et al., 1997. Risk of breast cancer associated with atypical hyperplasia of lobular and ductal types. Cancer Epidemiol Biomarkers Prev. 6: 297-301.

Kennedy M, Masterson AV, Kerin M et al., 2003. Pathology and clinical relevance of radial scars: a review. J Clin Pathol. 56: $721-724$.

Patterson JA, Scott M, Anderson N et al., 2004. Radial scar, complex sclerosing lesion and risk of breast cancer. Analysis of 175 cases in Northern Ireland. Eur J Surg Oncol. 30: 10651068.

Fasih T, Jain M, Shrimankar J et al., 2005. All radial scars/complex sclerosing lesions seen on breast screening mammograms should be excised. Eur J Surg Oncol. 31: 1125-1128.

Rabban JT, Sgroi DC. 2004. Sclerosing lesions of the breast. Semin Diagn Pathol. 21: 42-47.

Vijayalakhmi M, Rao JY, Shekar TY. 2016. Prevalence of benign breast disease and risk of malignancy in benign breast diseases. IOSR $\mathbf{J}$ of Dental and Med Sci. 15: 32 -36.

Kotepui M., Piwkham D., Chupeerach C., Songsri A., Charoenkijkajorn L. 2014. Epidemiology and histopathology of benign breast diseases and breast cancer in Southern Thailand. Eur J of Gynaecol Oncol. 35: 670-5. 
Lee M., Soltanian HT. 2015. Breast perspectives. Adolesc Health Med Ther. fibroadenomas in adolescents: current 6: $159-169$

\section{How to cite this article:}

Debasmita Chatterjee, Rathin Chakravarty, Bishaka Halder, Asutosh Kundu, Suparna Mukherjee and Satadal Das. 2019. Diagnosis and Treatment Procedures Involved for Young Female Patients having Fibroadenoma. Int.J.Curr.Microbiol.App.Sci. 8(01): 472-479. doi: https://doi.org/10.20546/ijcmas.2019.801.050 